\title{
Fragilidades Estruturais do Tratado Antártico
}

\author{
Friederick Brum Vieira
}

\begin{abstract}
Resumo: Este artigo pretende mostrar que o Tratado Antártico, que entrou em vigor em 1961, vem apresentando crescentes sinais de fragilidades como resultado da tensão não resolvida entre os interesses territorialistas e internacionalistas nele presentes. Argumenta-se que, não obstante aquele diploma internacional ter incorporado através do Protocolo de Madri, que entrou em vigor em 1998, importantes princípios de preservação ambiental, as reivindicações territoriais mantidas por vários países, entre eles os sul-americanos Argentina e Chile, minam os esforços no sentido de conservar a Antártica como um patrimônio ambiental da humanidade. $\mathrm{O}$ artigo esposa a ideia de que a ampliação de tais reivindicações no sentido das plataformas continentais por países reivindicantes torna urgente a reformulação do Tratado Antártico.
\end{abstract}

Palavras-chave: Sistema Antártico, Tratado Antártico, Protocolo de Madri, Territorialismo, Internacionalismo.

\begin{abstract}
This article intends to show that the Antarctic Treaty, which took effect in 1961, has been presenting mounting signals of fragilities as a result of the unsolved tension between territorialist and internationalist interests. It is argued that, despite that international agreement has incorporated through the Madrid Protocol, which took effect in 1998, important principles of environmental preservation, territorial reivindications kept by several countries - among them South American Argentina and Chile - undermine efforts aiming to keep Antarctica as a world natural asset. The article supports the idea that the widening of such reivindications toward continental platforms by claiming countries makes the revision of the Antarctic Treaty an urgent issue.
\end{abstract}

Keywords: Antarctic System, Antarctic Treaty, Madrid Protocol, Territorialism, Internationalism.

(*) Graduado em Geografia, História e Jornalismo pela Universidade Federal do Espírito Santo (Ufes), mestre em Ciência Política pela Universidade Federal Fluminense (UFF), mestre em História e mestre em Geografia pela Universidade do Estado do Rio de Janeiro (Uerj), doutor em Integração da América Latina pela Universidade de São Paulo (USP) e funcionário aposentado da Coordenação de Estruturas Territoriais - CET do Instituto Brasileiro de Geografia e Estatística - IBGE. O autor iniciou em 2007 um estágio no Scott Polar Research Institute, da University of Cambridge, no Reino Unido, seguido em 2008 de residência por dois semestres acadêmicos no Chile. No período, realizou várias viagens às regiões subantárticas da Argentina, do Chile e do Reino Unido como parte do trabalho de pesquisa para sua tese "Reivindicações territoriais de Argentina e Chile na Antártica", defendida em 2009.E-mail: friederi@uk2.net e friederi@voila.fr. Recebido em: 8.2.2010 e aceito em: 22.3.2010. 


\section{INTRODUÇÃo}

A Guerra Fria entre o campo capitalista liderado pelos Estados Unidos e o campo socialista liderado pela União Soviética encerrou-se com o desmantelamento político desta última, há quase 20 anos, fazendo desaparecer um império construído ao longo de séculos, e, mais recentemente, embora de maneira diferenciada, com a crise econômica que atingiu o primeiro, destruindo os fundamentos teóricos que serviram como suporte para a organização de um outro império ${ }^{(1)}$.

No entanto, esse período da História Contemporânea deixou alguns testemunhos, como os antagonismos ideológicos entre a Coréia do Norte e a Coréia do Sul, que teimam em desafiar a reconfiguração de poder ocorrida no Leste, além da manutenção de Cuba como peça de resistência dentro do sistema americano. Há, porém, um outro fato característico da Guerra Fria que vem escapando à maioria dos analistas: o Tratado

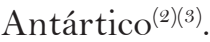

A origem mais remota do Tratado Antártico foi a comunidade científica internacional, que em 1957-58 promoveu o Ano Geofísico Internacional - AGI, ao longo do qual foram desenvolvidos estudos visando um melhor entendimento da dinâmica de processos naturais envolvendo a região circundante ao Polo Sul. Esse evento contou com a participação de cientistas de 12 países que haviam revelado tradição em pesquisas antárticas: África do Sul, Argentina, Austrália, Bélgica, Chile, Estados Unidos, França, Japão, Noruega, Nova Zelândia, Reino Unido e União Soviética.

Após o evento, a União Soviética negou-se a desmontar suas estações de pesquisa na Antártica alegando que os estudos nelas iniciados não haviam terminado e que precisavam ter continuidade. Em plena Guerra Fria, os Estados Unidos suspeitaram que a razão envolvesse a intenção de seu rival ideológico de instalar bases militares no continente, possivelmente estendendo às proximidades da América do Sul a corrida nuclear que já se desenrolava em outras partes do mundo.

Se materializada, essa hipótese se converteria num desafio à supremacia dos Estados Unidos no Hemisfério Ocidental, já que apenas dois anos após a Segunda Guerra Mundial,

(1) Ao retornar ao capitalismo, a partir de 1991, abandonando assim os princípios ideológicos que permitiram sua liderança sobre o campo socialista, a Rússia viu-se reduzida à influência de que dispunha no século XVIII, antes que o czar Pedro, o Grande, iniciasse o processo de expansão cujo auge foi a formação da União Soviética, no século XX. Já os Estados Unidos, ao determinarem em 2009 a intervenção governamental na sua própria economia, sepultaram a justificativa moral em favor da liberdade de mercado e da privatização, típica dos anos 90 e responsável por grande parte de seu papel sobre o campo capitalista ao longo do século XX. A utilização neste artigo do termo "império", portanto, não corresponde à acepção tradicional e sim à liderança sobre um campo global. As denominações também são usadas com certa frequência por pesquisadores da Guerra Fria. Disponível em: <www.americanempireproject.com> Acesso em: 13.1.2010 e <www.soviet-empire.com> Acesso em: 13.1.2010.

(2) Vieira (2009a, p. 167-193). O tex to completo do tratado está disponível no trabalho e em vários sítios eletrônicos da rede mundial de computadores, um dos quais o do próprio Sistema do Tratado Antártico. Disponível em: $<$ www.ats.aq> Acesso em: 13.1.2010.

(3) A denominação Tratado Antártico, utilizada neste artigo, resulta da tradução literal da denominação Antarctic Treaty, que foi incorporada pelo texto original do diploma em sua versão na língua inglesa e reproduzida em vários outros idiomas, como o espanhol. A referida denominação difere da denominação mais comumente usada em língua portuguesa, Tratado da Antártica, que o autor deste artigo considera imprópria, pois o continente Antártico não possui personalidade jurídica reconhecida por toda a comunidade internacional. 
em 1947, aquele país firmara com as nações latino-americanas um pacto contra uma eventual invasão soviética que obrigava todos os signatários a intervir em ajuda de qualquer parte afetada. Esse pacto recebeu a denominação em espanhol e português de Tiar — Tratado Interamericano de Assistência Recíproca.

A parte mais interessante do Tiar para este artigo é aquela que define os seus limites de abrangência, estendendo-se do Polo Norte ao Polo Sul e incluindo todo o continente americano. Assim, os Estados Unidos criaram uma área de proteção hemisférica que na prática incorporou várias partes da Antártica, do que resultou que o ingresso em seu interior de forças soviéticas equivaleria a uma invasão inimiga, com todas as consequências imagináveis.

Portanto, quando a União Soviética se negou a retirar suas bases da Antártica, isto soou como uma declaração antecipada de guerra. A alternativa ao confronto foi a convocação de todos os países que haviam participado do AGI para a discussão, seguida de elaboração, de um tratado internacional que resguardasse a região antártica de um conflito, o que aconteceu, inclusive, com a participação da delegação soviética. Nasceu desta forma, com a denominação de Tratado de Washington, o Tratado Antártico ${ }^{(4)}$.

\section{NA ORIGEM DO TRATAdo, O TERritorialismo}

Entre os 12 países que participaram do AGI, encontravam-se sete que já haviam manifestado interesse reivindicatório sobre o continente, o que à época não suscitou interrogações, pois as questões de fundo nacional eram facilmente eclipsadas pelo problema maior da competição ideológica e militar entre os campos capitalista e socialista. Esses sete países eram Argentina, Austrália, Chile, França, Noruega, Nova Zelândia e Reino Unido.

Ao longo de 30 anos o Tratado Antártico foi reputado pela proeza de conseguir manter todo um continente como espaço não territorializado, livre das armas nucleares e dedicado à ciência. Ao final desse período, foi fortalecido pela edição de um diploma adicional, o Protocolo de Madri ${ }^{(5)}$, que consagra a proteção ambiental do ambiente antártico. O Protocolo de Madri foi assinado na cidade que lhe emprestou o nome em 1991 e entrou em vigor em $1998^{(6)}$.

(4) Segundo Daniels (1973), o Tratado Antártico serviu como modelo diplomático de compatibilização de interesses internacionais divergentes e até conflitantes, numa época em que os mesmos eram especialmente agudos. Daniels foi funcionário do Departamento de Estado dos Estados Unidos, em cuja capacidade participou da discussão e elaboração do tratado, assinando-o como representante americano.

(5) Protocolo de Madri é a denominação mais comumente utilizada do Protocolo de Proteção do Meio Ambiente, formulado em complementação ao Tratado Antártico.

(6) O Protocolo de Madri compõe-se de um texto principal e mais seis anexos. Os quatro primeiros anexos entraram em vigor em 1998, junto com aquele diploma legal, o quinto passou a vigorar em 2002 e o sexto passou a ser mais tarde ratificado pelos países signatários. O texto está disponível em vários sítios eletrônicos da rede mundial de computadores, porém o do Governo Australiano, pelos comentários elucidativos que oferece, merece ser visitado em: <www.aad.gov.au> Acesso em: 13.1.2010. 
Torna-se necessário ressaltar que tanto o Tratado Antártico como o Protocolo de Madri, ademais de outros compromissos estabelecidos multilateralmente à jusante do primeiro, tiveram como origem a comunidade científica e constituem, hoje, o que se conhece como Sistema do Tratado Antártico, o qual, embora conte com a adesão de países, não se subordina a eles, não estando, além disso, vinculado à Organização das Nações Unidas — ONU. O termo "sistema" parece bastante adequado, pois se tratam de compromissos diferentes, porém agregados e, de certa forma, interdependentes ${ }^{(7)}$.

Todavia, o Tratado Antártico tem servido também como base para a organização de um sistema de poder, já que, acessoriamente àqueles compromissos, foram sendo criados órgãos com sentido funcional, ao ponto de permitir que se veja nos mesmos operações legislativas, executivas e até judiciárias ${ }^{(8)}$, onde os protagonistas, em vez de legisladores, administradores ou juízes, são cientistas.

À parte essa visão, o fato é que o Sistema do Tratado Antártico tem hoje, sob sua jurisdição, um continente com posição geopolítica estratégica pela interface singular com os três maiores oceanos, imensos recursos naturais, entre os quais se incluem os de base energética e, sobretudo, 14 milhões de $\mathrm{km}^{2}$ de área praticamente despovoada que, em alguns aspectos, reproduz a condição de outros continentes antes da colonização e, em outros, antecipa possíveis experiências no espaço exterior à Terra ${ }^{(9)}$.

(7) Além do Protocolo de Madri, são os seguintes os acordos conexos ao Tratado Antártico: Convenção para Conservação das Focas Antárticas, assinada em Londres em 1972, e que entrou em vigor em 1978; Convenção para Conservação dos Recursos Vivos Marinhos Antárticos, assinada em Camberra em 1980 e vigente desde 1982. Há acordos multilaterais, como a Convenção Internacional para a Regulamentação da Caça de Baleias, que embora estejam plenamente dentro do contex to do Tratado Antártico, foram assinados e passaram a vigorar antes dele, não sendo, por esta razão, considerados oficialmente como parte do Sistema do Tratado Antártico.

(8) O primeiro desses órgãos é a Reunião Consultiva do Tratado Antártico — RCTA, realizada bienalmente em um dos países aderentes, sendo integrada por representantes dos mesmos, tanto na forma de partes consultivas (com direito a voto), como das partes não consultivas (sem direito a voto). A diferença entre as duas categorias é feita pela amplitude e profundidade da interação das respectivas comunidades científicas com a Antártica, sobretudo, no que diz respeito ao desenvolvimento de pesquisas. A RCTA tem caráter deliberativo por consenso, podendo ser considerada como o "legislativo" antártico. O segundo desses órgãos é o Comitê Científico sobre Pesquisa Antártica (Scar, ou Scientific Committee on Antarctic Research), com integrantes apontados pela comunidade científica. Suas reuniões também são bienais, em geral, seguindo-se às reuniões da RCTA e nos mesmos países onde esta se realiza. O Scar tem caráter operativo, podendo ser considerado como o "executivo" do Tratado Antártico pois seu trabalho consiste em executar as decisões tomadas pela RCTA. O terceiro desses órgãos é o Comitê de Política Antártica — CPA, existente no âmbito do Protocolo de Madri e que se reúne paralelamente à RCTA, com representantes indicados pelos países aderentes. O CPA busca fazer com que as disposições do Protocolo de Madri sejam cumpridas e, por esta razão, pode ser considerado como o "judiciário" antártico. Embora este último órgão não disponha ainda de força coercitiva, tem a seu encargo fazer com que seja cumprido o Anexo 5 do Protocolo de Madri, que estabelece áreas do espaço antártico onde não é permitida a entrada sem autorização do Sistema do Tratado Antártico. Este tem ainda uma Secretaria, que funcionou sem uma sede permanente até 2004 mas que a partir daí - e seguindo-se a uma acirrada disputa política entre as partes consultivas argentina e britânica — instalou-se em Buenos Aires. A Secretaria do Sistema do Tratado Antártico se incumbe de preparar os encontros das RCTA, publicar seus documentos, servir de elo entre os membros do Tratado Antártico e fornecer informações ao público. Embora suas atribuições formais sejam diferentes, na prática o órgão atua como uma "presidência" para o Sistema do Tratado Antártico.

(9) Ver Sollie (1973). Em seu artigo, o autor estabelece um interessante paralelo entre a edição do Tratado Antártico e outros desenvolvimentos jurídicos afetos a espaços não territorializados, como o espaço exterior à Terra. Efetivamente, a Antártica tem servido para treinamento de pessoal em ambientes inóspitos, entre os quais se incluem astronautas brasileiros. Disponível em: <www.zenite.nu> Acesso em: 7.2.2010. 
A Antártica pode ser vista pelas lentes internacionalistas como um admirável mundo novo(10) gelado, uma vez que o que ali ocorre é inusitado: seu espaço é a última porção do globo terrestre não sujeita efetivamente à soberania de nenhum Estado-nação e, nessa condição, mantém-se como um enorme monumento natural destinado à ciência e à concórdia internacional.

No entanto, pelas lentes territorialistas, a Antártica segue sendo considerada como a bola da vez de interesses coloniais, tal qual em outros tempos foram a Ásia, a América, a África e a Oceania. Seu espaço está, em sua maior parte, fatiado por reivindicações territoriais dos sete países já referidos, a maioria dos quais, ironicamente, foram colônias no passado ${ }^{(11)}$. Todos esses países são membros originais e partes consultivas do Tratado Antártico.

\section{TERritorialismo E INTERNACIONALISMO, UMA DifícIL CONVIVÊNCIA}

Essa ambiguidade entre interesses territorialistas e internacionalistas ocorre porque o Tratado Antártico foi firmado como um instrumento destinado a evitar que a disputa geopolítica entre os Estados Unidos e a União Soviética, realizada durante a Guerra Fria, se projetasse, também, sobre o espaço circundante ao Polo Sul, e não para eliminar pressões reivindicatórias sobre ele.

Assim, o Tratado Antártico apresenta a virtude de resguardar a Antártica como um continente livre de atividades militares, mas, também, o defeito de reconhecer demandas territoriais sobre o continente. A virtude é consagrada pelo seu art. $1^{\underline{o}}$, e o defeito pelo art. $4^{\stackrel{0}{ }}$, como se segue:

Art. $1^{0}$

A Antártica será utilizada somente para fins pacíficos. Serão proibidas, inter alia, quaisquer medidas de natureza militar, tais como o estabelecimento de bases e fortificações, a realização de manobras militares, assim como experiências com quaisquer tipos de armas.

Art. $4^{\circ}$

1. Nada que se contenha no presente Tratado poderá ser interpretado como:

a) Renúncia, por quaisquer das Partes Contratantes, a direitos previamente invocados ou a pretensões de soberania territorial na Antártica;

b) Renúncia ou diminuição, por quaisquer das Partes Contratantes, a qualquer base de reivindicação de soberania territorial na Antártica que possa ter, quer como resultado de suas atividades ou de seus nacionais na Antártica, quer por qualquer outra forma;

(10) A expressão foi tomada emprestado do romance do escritor britânico HUXLEY, Aldous. Brave new world, o qual o autor antevê um futuro em que o mundo será governado por cientistas, e não políticos ou militares.

(11) Os quatro países que foram colônias no passado e que agora buscam converter a Antártica em parte de seus territórios de um modo compatível com o colonial são Argentina, Austrália, Chile e Nova Zelândia. 
c) Prejulgamento da posição de qualquer das Partes Contratantes quanto ao reconhecimento dos direitos ou reivindicações ou bases de reivindicação de algum outro Estado quanto à soberania territorial na Antártica.

2. Nenhum ato ou atividade que tenha lugar, enquanto vigorar o presente Tratado, constituirá base para proclamar, apoiar ou contestar reivindicação sobre soberania territorial na Antártica ou para criar direitos de soberania na Antártica. Nenhuma nova reivindicação ou ampliação de reivindicação existente, relativa à soberania territorial na Antártica, será apresentada enquanto o presente Tratado estiver em vigor.

O problema com essa ambiguidade entre territorialismo e internacionalismo no tex to do Tratado Antártico é que, passada a Guerra Fria e os antagonismos bilaterais nela contidos, reemergem agora, e com força crescente, os interesses multilaterais implícitos no Estado-nação. Os desafios ao Tratado Antártico podem ser observados sob diversas perspectivas, mas duas bastam para que os mesmos possam ser exemplificados.

\section{EXERCíCIOS MILITARES E AMPLIAÇÃo DE REIVINDICAÇÕES}

A primeira delas é a perspectiva militar. Argentina e Chile, países cujas bases de pesquisa antártica são oficialmente bases militares, realizaram em 2008 uma operação conjunta de suas Forças Armadas na Antártica ${ }^{(12)}$. Embora o objetivo tenha sido o congraçamento das tropas dos dois países, a operação conflita claramente com o art. $1^{\circ}$ do Tratado Antártico. Há notícias de que outros países, inclusive o Brasil, estejam utilizando a Antártica para operações militares de treinamento ${ }^{(13)}$.

A segunda perspectiva é a geopolítica. A ONU abriu prazo até 13 de maio de 2008 para que os países que desejassem ampliar os limites de suas águas territoriais definissem a amplitude de suas plataformas continentais. Países como Reino Unido e Noruega realizaram tal definição em espaço além da latitude de $60^{\circ} \mathrm{S}$, o que contraria o art. $4^{\circ}$ do Tratado Antártico, que dispõe que todo o espaço compreendido entre aquele paralelo e o Polo Sul está sob a jurisdição do Tratado Antártico e, assim, não pode ser territorializado.

O interesse dessa questão para o contexto latino-americano é que Antártica e América do Sul estão a menos de 1 mil quilômetros de distância ${ }^{(14)}$ e dois países desta última procla-

(12) Essa operação foi a Ejercício Confraternidad 2008 e foi realizada entre 15.8.2008 e 15.9.2008. Disponível em:

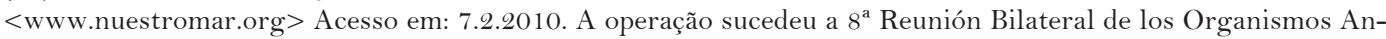
tárticos de los Ejércitos de Argentina y Chile, realizada no Comando Antártico Argentino, em Buenos Aires. Cabe destacar que Argentina e Chile, dois dos países mais territorialistas em relação à Antártica e que, como assinalado no texto principal, denominam suas bases de pesquisa no continente de "bases militares", mantêm tropas permanentemente nesses locais.

(13) Embora não comentem abertamente o assunto, vários outros países, além de Argentina e Chile, mantêm suas bases antárticas sob direção militar. Todos os países sul-americanos com presença no continente procedem desta forma, sendo que no caso do Brasil as operações ficam subordinadas ao Comando da Marinha - eventualmente com a participação do Comando da Aeronáutica em questões de logística. Operações de treinamento militar do Brasil na Antártica são relativamente frequentes, como a realizada em março de 2008, na qual morreu o sargento da Marinha Laércio de Melo Olegário, alegadamente, a primeira vítima das operações militares brasileiras no continente. Disponível em: <www.popa.com.br> Acesso em: 7.2.2010.

(14) As distâncias da Antártica para os demais continentes que se estendem pelo Hemisfério Sul são muito maiores: cerca de 3,6 mil quilômetros até a África e 2,2 mil quilômetros até a Oceania. 
mam soberania sobre praticamente o mesmo espaço antártico — que, por sua vez, é disputado também por uma potência européia, o Reino Unido. As reivindicações dos três países se sobrepõem sobre a região mais cobiçada do continente, a Península Antártica ${ }^{(15)}$.

Em sua expressão subantártica, a questão antártica ${ }^{(16)}$ já foi razão para uma guerra envolvendo o Reino Unido e a Argentina em 1982. Foi a Guerra das Falklands ou Malvinas, quando as paixões argentinas, decorrentes de uma soberania frustrada sobre o arquipélago desde 1833, levaram a uma invasão militar do território britânico, repelida dois meses depois por uma nutrida reação em defesa de interesses coloniais.

As alegações, feitas com certa frequência, de que a invasão foi decorrente do fato de a Argentina ser à época comandada por um regime militar, são insustentáveis: encontrando-se aquele país já há quase 20 anos em condição plenamente democrática, as pressões pela retomada das ilhas se mantêm, pois, como constatou o autor deste artigo em viagem pela região, elas não são originadas exclusivamente nos quartéis e sim na sociedade como um $\operatorname{todo}^{(17)}$.

Nas Ilhas Falklands ou Malvinas, o clima não é menos inamistoso. Quase 30 anos após o conflito, grande parte do território ainda está minado e o aeroporto internacional de Stanley, a capital, localizado dentro de uma base militar, segue sujeito à legislação que regula os segredos de Estado do Reino Unido ${ }^{(18)}$. Na bibliografia escrita por vários ilhéus relatando as agruras durante o conflito, destaca-se um sentimento que, talvez, resuma o clima psicológico: A good argie is a dead argie ${ }^{(19)}$.

Esses antagonismos não estão restritos às relações entre o Reino Unido e a Argentina. A Argentina e o Chile ainda mantêm pendências territoriais comuns, incluindo a que se refere às respectivas reivindicações antárticas. Tais pendências persistem informalmente, por meio de hostilidades recíprocas, mesmo em territórios cuja delimitação já se encontra definida por acordo bilateral, como no Canal de Magalhães e no Estreito de Beagle.

\section{Tratado Transformou-SE EM SISTEMA DE PODER}

A fragilidade do Tratado Antártico quanto às tensões não resolvidas entre internacionalismo e territorialismo parece clara e não há evidências de que possa diminuir, e sim

\footnotetext{
(15) O interesse sobre a Península Antártica de parte de Argentina, Chile e Reino Unido - entre vários outros países que ainda não o expressaram oficialmente, como Brasil e Uruguai - resulta, sobretudo, do fato de que essa região é a mais setentrional do continente, o que torna o acesso a ela mais fácil e permite que seu clima seja muito menos rigoroso que o do restante da Antártica, ao ponto de incluir uma porção temperada, não polar. Há na Península Antártica, além disso, uma série de áreas livres de gelo durante todo o ano, o que, em princípio, favoreceria eventuais projetos de colonização. Ver a respeito Vieira (2009b).

(16) A região antártica é definida pelo Tratado Antártico como aquela situada a partir da latitude de $60^{\circ} \mathrm{S}$; considera-se que a região subantártica, embora não determinada oficialmente, esteja entre as latitudes de $40^{\circ} \mathrm{S} \mathrm{e} 60^{\circ}$.

(17) Eventuais dúvidas quanto a isso podem ser resolvidas com uma visita ao monumento aos mortos argentinos no conflito, em Ushuaia, onde, exatamente junto da placa com o nome de todos eles, encontra-se a inscrição, visível de longe: Volveremos.

(18) Essa legislação é o British Official Secrets Act F391G.

(19) Do inglês, em versão livre: "Um argentino bom é um argentino morto". A expressão é bastante conhecida nas Ilhas Falklands ou Malvinas, tendo sido reproduzida em pelo menos um dos vários livros publicados sobre o conflito, como em Bound (2002).
} 
aumentar ${ }^{(20)}$. Isto porque, conforme já observado, o Sistema do Tratado Antártico está paulatinamente se transformando num sistema de poder, que, para se manter, necessitará criar - como qualquer outro Estado, na perspectiva westfaliana ${ }^{(21)}$ — os instrumentos necessários para essa manutenção.

Veja-se, nesse sentido, que o Protocolo de Madri definiu para a Antártica uma imensa reserva natural, cujas dimensões, a fim de que se possa ter um parâmetro comparativo, são de quase três vezes o tamanho da Amazônia brasileira ${ }^{(22)}$. No âmbito do diploma, foram estabelecidos seis anexos e, em um deles, o quinto, há previsão para a delimitação de zonas onde a entrada é proibida ou limitada. Note-se que esse zoneamento não está sendo estabelecido por um organismo multilateral de sentido global, como a ONU, mas por um conjunto de países signatários de um tratado que não representa o interesse de todo o planeta ${ }^{(23)} \mathrm{e}$ que tem, entre seus membros, sete países oficialmente reivindicantes de território no continente.

Essas zonas são em número de 66, das quais 60 serão Zonas Antárticas Especialmente Protegidas - Zaep — e seis Zonas Antárticas Especialmente Administradas — Zaea. Nas primeiras, a entrada será proibida, exceto para atividades científicas autorizadas; nas segundas, limitada, a fim de que se possa reduzir o impacto ambiental. Note-se que a autorização será dada pelo Sistema do Tratado Antártico, um organismo que não possui, sob a perspectiva do Direito Internacional, nem a condição estatal, nem de entidade multilateral global.

Ora, algum organismo terá que ter poder de polícia a fim de manter a proibição ou a limitação de acesso. Como a Antártica não está sob a soberania de nenhum Estado-nação e nem mesmo sob jurisdição da ONU, parece claro que tal incumbência ficará ao encargo do próprio Sistema do Tratado Antártico - o que, por sua vez, criaria um interessante problema legal, já que o Sistema do Tratado Antártico, não obstante sua multilateralidade, abrange

(20) Entre vários outros exemplos possíveis, em janeiro de 2010, um incidente envolvendo um navio de pesquisas japonês e uma embarcação de ambientalistas australianos deu a medida da incapacidade do Tratado Antártico de regular, até mesmo as relações entre seus membros — Japão e Austrália são partes consultivas e a Austrália é país reivindicante de território no continente. O navio japonês encontrava-se em águas antárticas capturando baleias para experimentos científicos quando foi interceptado pela embarcação australiana sob a alegação de que o produto da captura seria, na realidade, destinado ao mercado, em contraste com a posição internacional subscrita pelo Governo Japonês quanto à preservação da espécie. O navio japonês, então, sem modificar o curso previamente estabelecido, projetou-se sobre a embarcação australiana, destruindo sua proa e levando-a ao afundamento. O incidente foi divulgado extensivamente, como em Ady Gil sinks after whaling skirmish. Disponível em: <www.abc.net.au> Acesso em: 13.1.2010.

(21) Entende-se por perspectiva westfaliana aquela que foi cunhada no século XVII tendo como base a chamada Paz de Westfalia. Esse conjunto de acordos tecidos ao longo de quatro anos e, finalmente, assinado em 1648, pôs fim a conflitos europeus, principalmente entre o que é, hoje, a Alemanha e a França. Alegadamente, sua principal virtude foi consagrar às, então, 350 unidades que mais tarde viriam a formar o Estado-nação na Alemanha, o princípio da soberania territorial. A Paz de Westfalia também serviu como fundamento do Estado-nação no que se refere ao equilíbrio de poder entre Estados-nação, garantido pela força militar.

(22) A porção brasileira da Amazônia é de cerca de 5,5 milhões de $\mathrm{km}^{2}$, enquanto a Antártica tem 14 milhões de $\mathrm{km}^{2}$. Para uma comparação entre o espaço antártico e o de outros continentes, ver RUBIN, Jeff. Antarctica. London: Lonely Planet, 2005. p. 85.

(23) O Tratado Antártico reúne 47 membros, entre partes consultivas (28) e não consultivas (19). Como existem 194 países no mundo, isso corresponde a apenas 24,2 \% do total. Informações mais completas encontram-se em publicações como Secretaría del Tratado Antártico (2008). 
menos de um quarto dos países do mundo. Assim, hipoteticamente, cidadãos de um país não membro não teriam qualquer obrigação quanto a respeitar suas disposições.

Disso decorrem duas questões relevantes, uma quanto à necessidade de uma polícia antártica; outra, como seu corolário lógico e inevitável, a legitimidade e, mesmo, a legalidade desse eventual organismo. Talvez, sobrepassando esses problemas esteja um terceiro, o da instalação nas imensidões do Sul do planeta, de maneira absolutamente singular, de um tipo de organização que, tendo como origem a comunidade científica internacional, está conseguindo estabelecer um sistema de poder sobre todo um continente.

Imaginar o funcionamento de tal sistema daria margem a incontáveis conjecturas ${ }^{(24)}$, porém, o que este artigo buscou fazer, foi tão somente discutir a inadequação do Tratado Antártico para dar cabo dessa nova realidade, em especial, pela sua incapacidade estrutural de resolver a tensão entre internacionalismo e territorialismo, mas, igualmente, por não prever mecanismos que permitam a execução de suas próprias disposições no contexto atual.

De fato, não há como se manter um diploma legal que, por um lado, consagra o continente antártico como reserva ambiental para a humanidade e, por outro, reconhece as reivindicações territoriais de soberania que, tornadas efetivas, irão retalhá-lo, colocando em oposição, e talvez mesmo em confronto, países com reivindicações sobrepostas — Argentina, Chile e Reino Unido reivindicam a Península Antártica, enquanto Austrália e Noruega o fazem quanto à Terra da Rainha Maud.

Torna-se sensato e necessário, além de urgente, desta maneira, iniciar uma rediscussão do Tratado Antártico. Pelo viés internacionalista, essa rediscussão poderia incluir o objetivo de fazer com que todos os países reivindicantes abrissem mão de suas postulações, possibilitando a construção de uma nova organização internacional que viesse algum dia servir de exemplo para o desmonte do Estado-nação e a construção de um Estado unitário a nível global.

Pelo viés territorialista, a rediscussão do Tratado Antártico poderia incluir o objetivo de resolver as postulações dos países que acreditam ter direito sobre o espaço antártico, permitindo que os mesmos estendessem sua soberania ao continente e fizessem dos novos territórios o que melhor lhes conviesse. Ou, então, realizar uma rediscussão mais ampla sobre o espaço continental, possivelmente incluindo postulações não oficiais de países individualmente ou até em grupo $^{(25)}$.

(24) Uma dessas conjecturas foi realizada ainda durante a Guerra Fria, por K. Fedorov, um membro da Academia de Ciências da União Soviética que imaginou a Antártica como cenário para experiências de coexistência pacífica entre seu país e os Estados Unidos. Ver, a respeito em Fedorov (1973).

(25) A chamada "Teoria da Defrontação", inicialmente defendida pelo Brasil, mas que, posteriormente ganhou adeptos em países oficialmente não reivindicantes de território antártico, como Equador, Peru e Uruguai, propõe que a Antártica seja dividida entre todos os continentes localizados no Hemisfério Sul: América do Sul, África e Oceania. Um desdobramento dessa ideia estabelece que um eventual setor sul-americano seja fatiado entre os países que tenham litoral voltado para a Antártica: Argentina, Brasil, Chile, Equador, Peru e Uruguai. A fórmula incorpora um criativo mecanismo de ampliação da nesga de cada país: em vez do litoral propriamente dito, contam para a fixação da linha de interface também as ilhas oceânicas de cada país. Essa “teoria”, decerto, acrescenta complicadores à questão territorialista antártica, o principal deles o que faz com que a Península Antártica, já disputada pela Argentina, pelo Chile e pelo Reino Unido, passe a sê-lo também por Brasil e Uruguai. Além disso, torna a Antártica 
Nenhuma dessas abordagens está isenta de riscos. A adoção da primeira, isto é, o internacionalismo, colocará à prova o sistema westfaliano, possivelmente lançando sombras de dúvidas sobre institutos solidamente consolidados e que, bem ou mal, têm ancorado a ordem mundial nos últimos quatro séculos, como a soberania estatal. A adoção da segunda, ou seja, o territorialismo, abrirá um capítulo da corrida colonial que se julgava encerrada especialmente com a independência das colônias britânicas e francesas na primeira metade do século XX, além de antepor forças que já se defrontaram no passado por razões de território.

\section{Conclusão}

A questão antártica está na ordem do dia do ponto de vista das relações internacionais, pois, como visto, transita sobre problemas importantes para todo o planeta, tanto no âmbito ambiental como da segurança. A ambigüidade implícita no Tratado Antártico, que a um só tempo consagra o continente como patrimônio natural global e reconhece reivindicações territoriais sobre seu espaço, torna esse trânsito sensível e mesmo arriscado, uma vez que mantém em permanente confronto interesses territorialistas e globalistas.

A percepção de que o Tratado Antártico precisa ser reformulado para resolver essa contradição não é apenas do autor deste artigo. Já haviam se manifestado antes, nesse sentido, várias autoridades, entre elas o ministro das Relações Exteriores da Ucrânia, V. Ogryzko, por ocasião da $31^{\text {a }}$ Reunião das Partes Consultivas, ocorrida em Kiev, em 2.6.2008 ${ }^{(26)}$. Manifestações menos diplomáticas podem ser colhidas na rede mundial de computadores, onde, por exemplo, já se fala em "guerra inevitável”(27).

Uma apreciação bastante ponderada foi feita pelo cientista político Ricardo Israel Zipper, da Universidade do Chile, que considerando a importância da Antártica pelas enormes reservas de água doce que contém, chamou a atenção para o fato de que nenhum dos sete países reivindicantes apresentou, ao longo de toda a vigência do Tratado Antártico, por mais de meio século, qualquer evidência de que se disponha a desistir de suas pretensões territoriais $^{(28)}$.

O presente artigo, portanto, se encerra com um repto para que a rediscussão do Tratado Antártico seja iniciada, sem demora, e pela sua parte mais sensível: a remoção da contradição nele inclusa, seja pela efetivação do continente como reserva natural, seja pela sua divisão em glebas territoriais pelos países reivindicantes. Obviamente, uma terceira alternativa não estaria descartada: a divisão do continente em diferentes reservas ambientais, uma para cada país reivindicante.

\footnotetext{
o segundo palco de confrontos entre Chile e Peru, países que já foram à guerra duas vezes por limites em seus territórios sul-americanos e que, desde poucos anos atrás, sem terem resolvido adequadamente as pendências anteriores, inauguraram uma outra, quanto a limites sobre o mar territorial. Quanto à “Teoria da Defrontação”, ver Castro (1976). No que toca a reivindicações territoriais não oficiais sobre a Antártica há vários exemplos disponíveis, entre eles o do Uruguai, em Crawford (1974).

(26) Ver o comentário disponível em: <http://mfa.gov.ua> Acesso em: 13.1.2010.

(27) Ver a expressão disponível em: <www.mtholyoke.edu> Acesso em: 13.1.2010.

(28) Ver o artigo disponível em: <http://english.safe-democracy.org> Acesso em: 13.1.2010.
} 


\section{REFERÊNCIAS BIBLIOGRÁFICAS}

ADY GIL SINKS AFTER WHALING SKIRMISH. Disponível em: <http://www.abc.net.au> Acesso em: 13.1.2010.

BOUND, Graham. Falkland islanders at war. Barnsley: Pen \& Sword, 2002.

CASTRO, Therezinha de. Rumo à Antártica. Rio de Janeiro: Freitas Bastos, 1976.

CRAWFORD, Leslie. Uruguay atlanticense y los derechos a la Antartida. Montevideo: Monteverde, 1974 .

DANIELS, Paul. The Antarctic treaty. In: LEWIS, Richard S.; SMITH, Philip M. (eds.). Frozen future. A prophetic report from Antarctica. Intr. Walter Sullivan, New York Times Science editor.,New York: Quadrangle, 1973.

FEDOROV, K. Experimental proving ground for peaceful coexistence and international collaboration. In: LEWIS, Richard S.; SMITH, Philip M. (eds.). Frozen future. A prophetic report from Antarctica. Intr. Walter Sullivan, New York Times Science editor, New York: Quadrangle, 1973.

RUBIN, Jeff. Antarctica. London: Lonely Planet, 2005, p. 85.

SECRETARÍA DEL TRATAdo ANTÁRTiCO. Sistema del Tratado Antártico. Buenos Aires: Secretaria del Tratado Antártico, 2008.

SOLLIE, Finn. The political experiment in Antarctica. In: LEWIS, Richard S.; SMITH Philip M. (eds.). Frozen future. A prophetic report from Antarctica. Intr. Walter Sullivan, New York Times Science editor, New York: Quadrangle, 1973.

VIEIRA, Friederick Brum. Fronteiras do Sul: reivindicações territoriais da Argentina e do Chile na Antártica. São Paulo, 2009. Tese (Doutorado) - Programa de Pós-graduação em Integração da América Latina da Universidade de São Paulo.

. Sistema antártico: 50 anos de construção de um sistema de poder. In: Programa e resumos do $17^{\circ}$ Simpósio Brasileiro de Pesquisa Antártica — SBPA. São Paulo: USP, 29.9.2009 a 1º.10.2009.

\section{Links da internet}

<http://english.safe-democracy.org > Acesso em: 13.1.2010.

<http://mfa.gov.ua> Acesso em: 13.1.2010.

<http://www.aad.gov.au> Acesso em: 13.1.2010.

<http://www.americanempireproject.com> Acesso em: 13.1.2010.

$<$ http://www.ats.aq> Acesso em: 13.1.2010.

<http://www.mtholyoke.edu> Acesso em: 13.1.2010.

<http://www.nuestromar.org> Acesso em: 7.2.2010.

<http://www.popa.com.br> Acesso em: 7.2.2010.

<http://www.soviet-empire.com> Acesso em: 13.1.2010.

<http://www.zenite.nu> Acesso em: 7.2.2010. 